\title{
Development of a Decision Support System (DSS) for Fitter Mechanics on Bulldozer Power Failure Maintenance: Case Study of Komatsu and Cummins Engines
}

\author{
Basil O. Akinnuli ${ }^{1} \&$ Mayokun Akinnubi ${ }^{1}$ \\ ${ }^{1}$ Mechanical Engineering Department, Federal University of Technology, Akure, Ondo State, Nigeria \\ Correspondence: Basil O. Akinnuli, Mechanical Engineering Department, Federal University of Technology, \\ Akure, Ondo State, Nigeria. Tel: 234-803-465-9522. E-mail: ifembola@yahoo.com
}

Received: April 18, 2014 Accepted: June 19, 2014 Online Published: October 26, 2014

doi:10.5539/emr.v3n2p20 URL: http://dx.doi.org/10.5539/emr.v3n2p20

\begin{abstract}
Maintenance plays an important role in the life span of equipment. The cost incurred during maintenance of machineries affects the service cost of the equipment. In other to reduce the cost and time wastage, effective troubleshooting tool is required. Power failure in earth moving equipment arises when the front-mounted "dozer" blade cannot push soil forward and create a level surface for construction site. This problem needs to be solved, so as to increase the equipment life span and productivity. This research has established that power failure in earthmoving equipment (bulldozer) results from a number of causes and the causes have been identified as faulty: torque converter, transmission system, steering system, air cleaner, turbo charger, fuel filter, injector, high water temperature and dust indicator. The maintenance service card (job card) for recording the maintenance carried out on the machine used as case study was visited. Through this, the historic data of frequency of occurrence of each problem throughout the year was collected as it affected the machine under study. Probability tree model was developed as predicting tool based on the historic information collected from the job card of the machine. Based on this probability tree, a logic was developed which lead to software algorithm development. Through this algorithm, a software was developed to enhance the speed of computation and making decision available speedingly using C \# (pronounced as C sharp) computer language because of its versatility and friendly nature. The user interface of the Knowledge based system is basically divided into analyses and troubleshooting, the analyses ask the operator questions related to lack of power in the machine, and the troubleshooting tests were carried out as it affects: transmission, torque converter, steering, clutch and brake system problems. The system gave a thorough maintenance breakdown analysis of power failure of the engine under study. The decision support system has an advantage of providing the maintenance engineer a knowledge of the probable causes of problems and the required solution; however this depends on the response of the user to the questions asked in the user interface. The solutions proffered by this decision support system were evaluated by compared with the proffered solutions in the manual of the machine under study and it was found to be the same. In essence, it is recommended that this system should be used in situations where the service technicians are knowledgeable to answer the questions in the user interface of the system. The use of decision support system to solve power failure problem can result to reduction in manpower, increase assurance of project completion in time and is therefore applicable and recommended for use in manufacturing and construction industries where optimum profitable services are mostly expected.
\end{abstract}

Keywords: decision support system, power failure causes, solutions, case study, artificial intelligent, bulldozer maintenance, software, development

\section{Introduction}

Equipment maintenance is a broad term used to describe the various processes that are employed to keep equipment in proper working condition. Equipment fails because its physical substance and structure cannot support the last duty required of it as claimed by (Leo, 1992; Nyberg, 1999). In other words, a final incident destroys it because it is not physically able to withstand that incident. In some cases, the end of an equipment's life is instantaneous and without warning. Many times there is a gradual worsening of performance that can be detected. (Akinnuli, 2009; Lars, 2004) 
A decision support system is a computer program that simulates the judgement and behaviour of a human or an organization that has expert knowledge and experience in a particular field (Akinnuli \& Olaleye, 2013). It is a computer application that performs a task that would otherwise be performed by a human expert. Decision support systems are part of a general category of computer applications known as artificial intelligence (Cornelius, 2002; Ganglui et al., 2004). To design a decision support system, one needs a knowledgeable engineer, an individual who studies how human experts make decisions and translates the rules into terms that a computer will understand (Clancey, 1984; Fink et al., 1984; Ying, 1998; Walwijk, 2000).

An artificial intelligence based system coverts the knowledge of an expert in a specific subject into a software code (Nyberg, 1999) and (Lugar \& Stubblefield, 2004). This code can be merged with other codes (based on the knowledge of other experts) and used for answering questions (queries) submitted through a computer (Hofman et al, 1988; Waterman, 1986; Charles, 2002). Decision support systems typically consist of three parts: A knowledge base which contains the information acquired by interviewing experts, and logic rules govern how that information is applied; an inference engine that interprets the submitted problem against the rules and logic of information stored in the knowledge base: and an Interface that allows the user to express the problem in a human language such as English (Stuan \& Sauter, 2006).

It has already been seen that different tasks in engineering problem solving require different computational tools. Inference or deduction from a set of facts, which simulate intelligent decision making, plays a major role in many problem-solving tasks. Like design, activities such as planning and management also can be improved with the use of intelligent tools. Development of comprehensive software solutions in many engineering disciplines requires a seamless integration of different types of computational tools (Newton et al., 1983). In addition, adaptation of problem solving to varying environments and requirements can be easily achieved using techniques provided by AI and decision support systems (Bylander et al., 1983; Fijany et al., 2002; Olmstadt, 2000).

Any problem-solving process has to be transparent to the engineer. This requires that the model adopted should be simple and the process carried out in the most natural manner. It minimizes the number of transformations that the information goes through resulting in retention of clarity and simplicity of implementation (FASMAN, 2006; Garcia, 2004; Olofsson, 2000). Expert(s) in this field needs long years of accumulated maintenance knowledge. As years are passing by, the old experts are reducing in number due to old age or death. The younger ones are not ready to stay that too long to acquire knowledge, and seeking shortest means for problem solving. In addition to these, technology is growing towards paperless means of communication which has been phasing out paper maintenance manual gradually. Hence, the development of this decision support system. This will aid reduction cost of maintenance, manpower and down time. It will make knowledge available in an easy way as well as meeting the paperless growth in communication technology. This will be a rationale of keeping the long time acquired experience of the experts, encouraging the young growing maintenance engineers, and fitter mechanics in their choosen career as plant maintenance engineer and fitter mechanics. In addition to these, this research is rebranding the paper manual now available towards paperless technology for future use.

\section{Method}

In achieving the stated objectives of this research, a comprehensive literature review was carried out on the causes and remedy of problem associated to lack of driving power in earth moving equipment. The identified causes of power failure was analysed by developing a probability tree. A logic chart (flow chart) was developed to analyse the problems and solutions detected; thereafter a software was developed and applied to solve the problems of power failure in earth moving equipment. The developed system was evaluated by comparing the predicted solution(s) to each identified problem with the solution(s) in the available paper maintenance manual of the bulldozer.

\subsection{Identified Causes of Power Failure}

Lack of driving power in earth moving equipment is basically due to neglected maintenance, engine problem or power train problems.

\subsubsection{Pre-investigating Approach of Power Failure}

In essence to troubleshoot the problems in the machine, the following question have to be answered; (a) How much driving power is lacking? (b) Is there a distinct lack of driving power compared with another similar machine? (c) Has the power train or engine been repaired recently? (d) What is the service meter reading? (e) What is the kind of soil at the job site (rock, clay, sand or general soil)?

Generally, rolling resistance decreases on sand, clay, rock and general soil must be shifted down to $1^{\text {st }}$ or $2^{\text {nd }}$ gear 
when performing the same job on clay or rocky ground. (f) Was periodic maintenance performed as specified? (g) Is the machine is correctly operated? Improper selection of speed range, forcing the machine to handle a heavy load exceeding the capacity, etc. will lower the efficiency of the machine. This will cause the operator to mistakenly feel the machine lacks driving power. In essence a flow chart was developed using the probable causes of power failure in earth moving equipment.

\subsubsection{Causes of Power Failure in Earth Moving Equipment}

These causes were identified by reasons of questionnaire development and distribution to the fitter mechanics, workshop maintenance engineers, maintenance engineers, and manufactures of this system as will as interview one operators attached to this system and reading of some available maintenance manual. Based on these, the following were found to the causes of power failure: fuel below low marking, water mixed with fuel, engine and transmission oil levels not at the normal level, leakages from fuel or oil piping, clogging of air vent hole in the fuel tank cap, dust indicator operating below service level; cooling water level normal, engine water temperature not within normal operating range, torgue converter oil temperature and pressure not within operating range, quick start of the machine when transmission control lever is shifted from one position to another, clogging of fuel fitter element and wrong injection teming.

These identified problems were identified with some machine components this helps to classified them as: Torgue Converter (TC), Transmission System (TS), Steering System (SS), Air Cleaner (AC), Turbo Charger (TCH), Fuel Fitter (FF), Injector (IN), Water Temperature (WT) and dust indicator problems (DI).

These were shown in table 1 and the probabilities of their occurrence from the historical data collected from the maintenance job card of the machine are as shown in Table 2 to 9.

Table 1. Used symbols and meaning

\begin{tabular}{|c|c|c|}
\hline $\mathbf{S} / \mathbf{N}$ & SYMBOL & INTERPRETATION \\
\hline 1 & TC 1 & Excessive oil spurted from filter \\
\hline 2 & $\mathrm{TC} 2$ & High oil temperature in the converter \\
\hline 3 & TC 3 & Burnt oil \\
\hline 4 & TS 1 & Poor responsiveness of machine to control lever position \\
\hline 5 & TS 2 & Lack of Power due to backward motion \\
\hline 6 & TS 3 & Oil pipe leakage \\
\hline 7 & SS 1 & Snaky travelling during low load \\
\hline 8 & SS 2 & Slow disengagement of steering clutch \\
\hline 9 & SS 3 & Fail in operation of steering brake \\
\hline 10 & AC 1 & Air cleaner element clogging \\
\hline 11 & AC 2 & Air muffler malfunction \\
\hline 12 & TCH 1 & Improper clearance and lack of smooth rotation \\
\hline 13 & TCH 2 & Seizing of turbine shaft \\
\hline 14 & TCH 3 & Impeller interfering with casing \\
\hline 15 & FF 1 & Filter element clogging \\
\hline 16 & FF 2 & Water mixed with fuel \\
\hline 17 & FF 3 & Fuel pipe leakage \\
\hline 18 & IN 1 & Injector clogging \\
\hline 19 & IN 2 & Plunger seizing \\
\hline 20 & IN 3 & Nozzle clogging \\
\hline 21 & IN 4 & Nozzle crushed \\
\hline 22 & WT 1 & High Temperature of water \\
\hline 23 & WT 2 & Low water level in radiator \\
\hline 24 & DI 1 & Low service level \\
\hline
\end{tabular}

Table 2 to Table 10 showed the identified problems as well as the rate of occurrence (frequency) and their probabilities. 
Table 2. History of power failure due to torque converter

\begin{tabular}{lccc}
\hline Power failure causes & Number of times it occurred & Fractional probability & Probability \\
\hline TC 1 & 6 & $6 / 12$ & 0.500 \\
TC 2 & 4 & $4 / 12$ & 0.333 \\
TC 3 & 2 & $2 / 12$ & 0.167 \\
\hline
\end{tabular}

Table 3. History of power failure due to transmission systems

\begin{tabular}{lccc}
\hline Power failure causes & Number of times it occurred & Fractional probability & Probability \\
\hline TS 1 & 6 & $6 / 15$ & 0.400 \\
TS 2 & 4 & $4 / 15$ & 0.267 \\
TS 3 & 5 & $5 / 15$ & 0.333 \\
\hline
\end{tabular}

Table 4. History of power failure due to steering systems

\begin{tabular}{lccc}
\hline Power failure causes & Number of times it occurred & Fractional probability & Probability \\
\hline SS 1 & 5 & $5 / 14$ & 0.357 \\
SS 2 & 6 & $6 / 14$ & 0.429 \\
SS 3 & 3 & $3 / 14$ & 0.214 \\
\hline
\end{tabular}

Table 5. History of power failure due to air cleaner

\begin{tabular}{lccc}
\hline Power failure causes & Number of times it occurred & Fractional probability & Probability \\
\hline AC 1 & 5 & $5 / 12$ & 0.417 \\
AC 2 & 7 & $7 / 12$ & 0.583 \\
\hline
\end{tabular}

Table 6. History of power failure due to turbo charger

\begin{tabular}{lccc}
\hline Power failure causes & Number of times it occurred & Fractional probability & Probability \\
\hline TCH 1 & 4 & $4 / 12$ & 0.333 \\
TCH 2 & 6 & $6 / 12$ & 0.500 \\
TCH 3 & 2 & $2 / 12$ & 0.167 \\
\hline
\end{tabular}

Table 7. History of power failure due to fuel filter

\begin{tabular}{lccc}
\hline Power failure causes & Number of times it occurred & Fractional probability & Probability \\
\hline FF 1 & 8 & $8 / 17$ & 0471 \\
FF 2 & 6 & $6 / 17$ & 0.353 \\
FF 3 & 3 & $3 / 17$ & 0.176 \\
\hline
\end{tabular}

Table 8. History of power failure due to water temperature

\begin{tabular}{lccc}
\hline Power failure causes & Number of times it occurred & Fractional probability & Probability \\
\hline WT 1 & 6 & $6 / 15$ & 0.400 \\
WT 2 & 9 & $9 / 15$ & 0.600 \\
\hline
\end{tabular}

Table 9. History of power failure due to dust indicator

\begin{tabular}{lccc}
\hline Power failure causes & Number of times it occurred & Fractional probability & Probability \\
\hline DI 1 & 7 & $7 / 7$ & 1.000 \\
\hline
\end{tabular}

Table 10. History of power failure due to injector

\begin{tabular}{lccc}
\hline Power failure causes & Number of times it occurred & Fractional probability & Probability \\
IN 1 & 5 & $5 / 14$ & 0.357 \\
IN 2 & 6 & $6 / 14$ & 0.429 \\
IN 3 & 2 & $2 / 14$ & 0.143 \\
IN 4 & 1 & $1 / 14$ & 0.071 \\
\hline
\end{tabular}




\subsection{Material Requirements}

In order to run the developed support system successfully on a computer, the following prerequisites must be met: (1) Operating system: Windows 2000, NT, Server, XP professional, Vista Ultimate and Windows 7, (2) Processor speed: At least 500MHz. (3) RAM: At least 256MB. and (4) Hard disk space: At least 2GB free.

The above enumerated prerequisites are mandatory so as to enable user friendliness as well as the optimum performance of the program.

\subsection{Software Development Tools}

The computer language used for programming the developed model is C\#. (pronounced see sharp) is a multi-paradigm programming language encompassing strong typing, imperative, declarative, functional, generic, object-oriented (class-based), and component-oriented programming disciplines. It was developed by Microsoft within its .NET initiative and later approved as a standard by ECMA (ECMA-334) and ISO (ISO/IEC 23270). $\mathrm{C \#}$ is one of the programming languages designed for the Common Language Infrastructure. $\mathrm{C \#}$ is intended to be a simple, modern, general-purpose, object-oriented programming language. Its development team is led by Anders Hejlsberg. The most recent version is C\# 4.0, which was released on April 12, 2010. There are so many programming languages that can also be used for software development but due to C\#'s versatility, efficiency as well as its user friendly interface, it is a much more preferred programming language in the world of software development.

During the usage of the program, the operator is expected to answer some questions before the procedure on failure detection and analysis. It is then required of the operator to define the specific area where the symptom reflects before the program specifically analyzes the failure and then proffers solution to the failure.

\subsection{Assumptions for the Software Development}

The following assumptions were made during the development of this program: (1) The structure of the program is strictly derived from experts' knowledge. (2) The fitter mechanic must have a previous knowledge about bulldozer work equipment operations in order to be able to interpret proffered solutions and carry it out. (3) The fitter mechanic must be computer operation proficient. (4) The fitter mechanic must be able to carry out proffer solutions to the problems suggested by the decision support system

\subsection{Software Design Classes}

The diverse design classes obtained from the software developed are listed thus: (1) Opening of the software. (2) Welcome Screen, log on, and registration. (3) Description of each of the interface. (4) Coding environment. (5) Data entry form. (6) Result and correction procedures.

Microsoft Visual Studio interface consists of the title bar, the menu far, the standard tool bar, the ribbon or tool bar and the property bar, workspace. The interface is detailed to work with the C\# interface makes the environment ready for the necessary coding. The welcome screen, log on and register interface gives the user an avenue for personal data inputs. The coding interface is the area designed to accommodate the commands, instructions and codes are written for the development of the software.

The data entry form contains codes required for accepting appropriate data items, performs necessary computation on these data items and then saves the processed data into the appropriate table in the database. The result sheet is the form that contains the outcome of the computation after necessary processing has been done.

\subsection{Software Application}

The picture below is the concise of all the problems that can cause lack of sufficient power in bulldozer work equipment. 


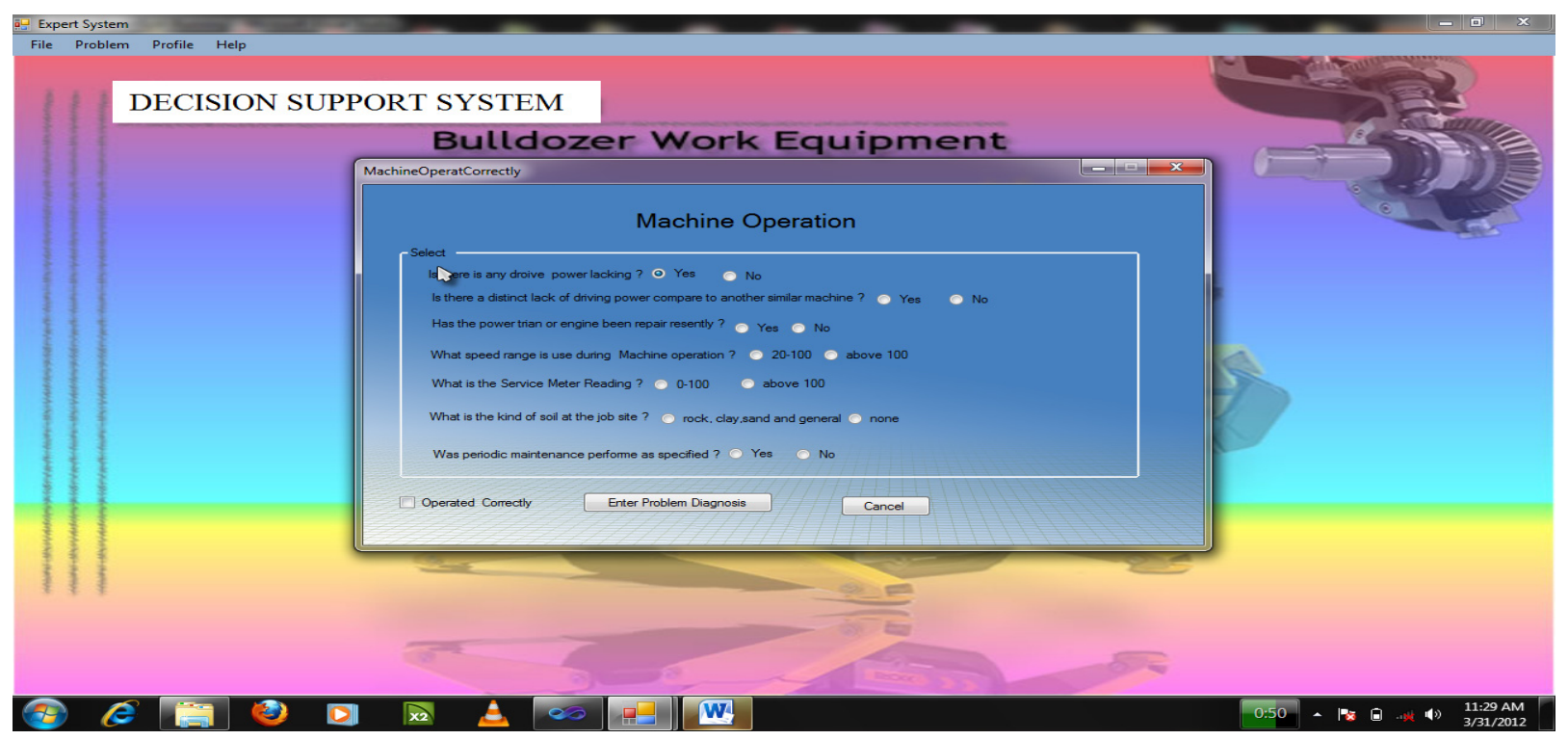

Figure 1. Summary of the various machine operations in bulldozer work equipment

From the Figure 1, this page displays immediately the operator launches the diagnose section of the program which in turn prompts the operator to select the corresponding suspected area(s) of machine operation that needs to be corrected in the machine which is dissected into seven sections. Each section will be addressed according to the necessary steps to be taken by the operator as well as the order in which the program has been designed.

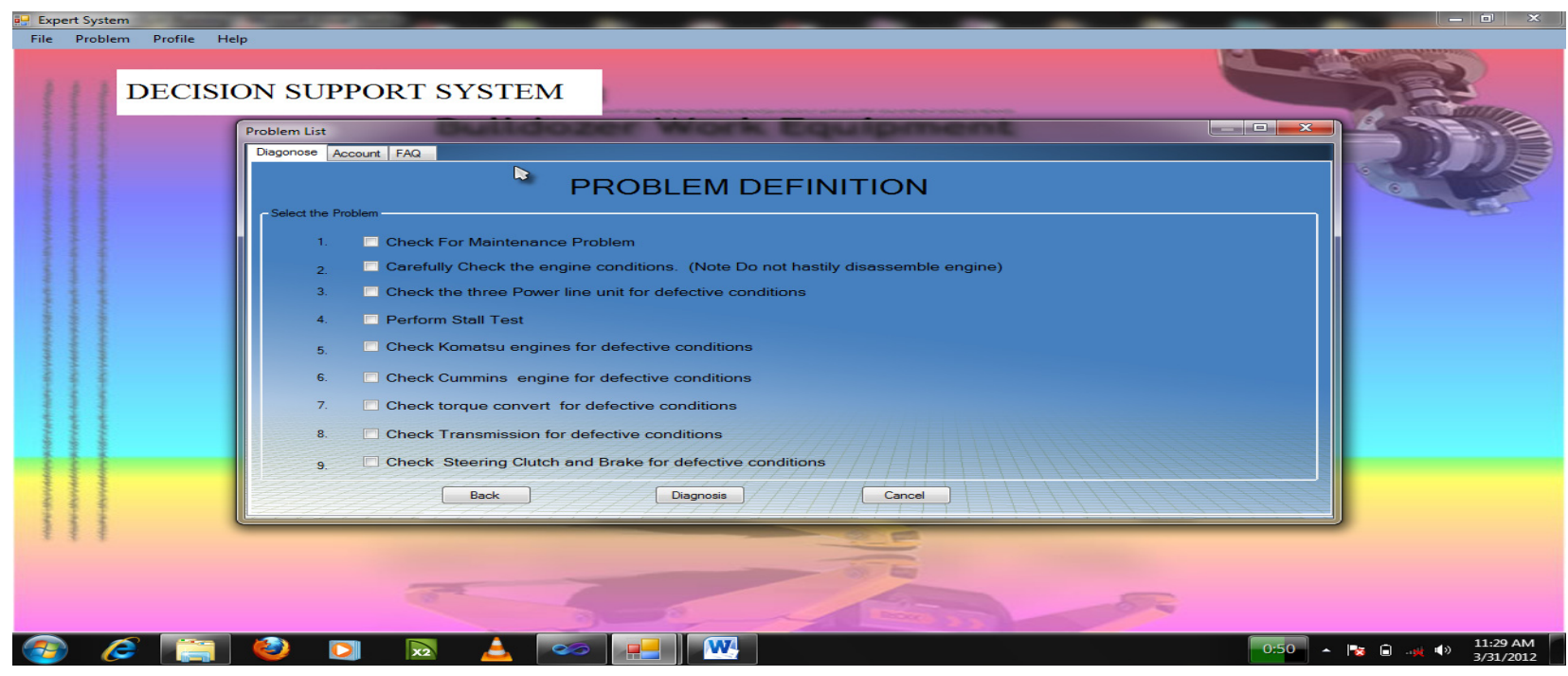

Figure 2. The problem definition page

Figure 2 describes the problem definition stage where the operator is expect to have prior knowledge of each problems defined at this stage. In this stage, a selection will automatically lead the operator to the expected solution page in the program. 


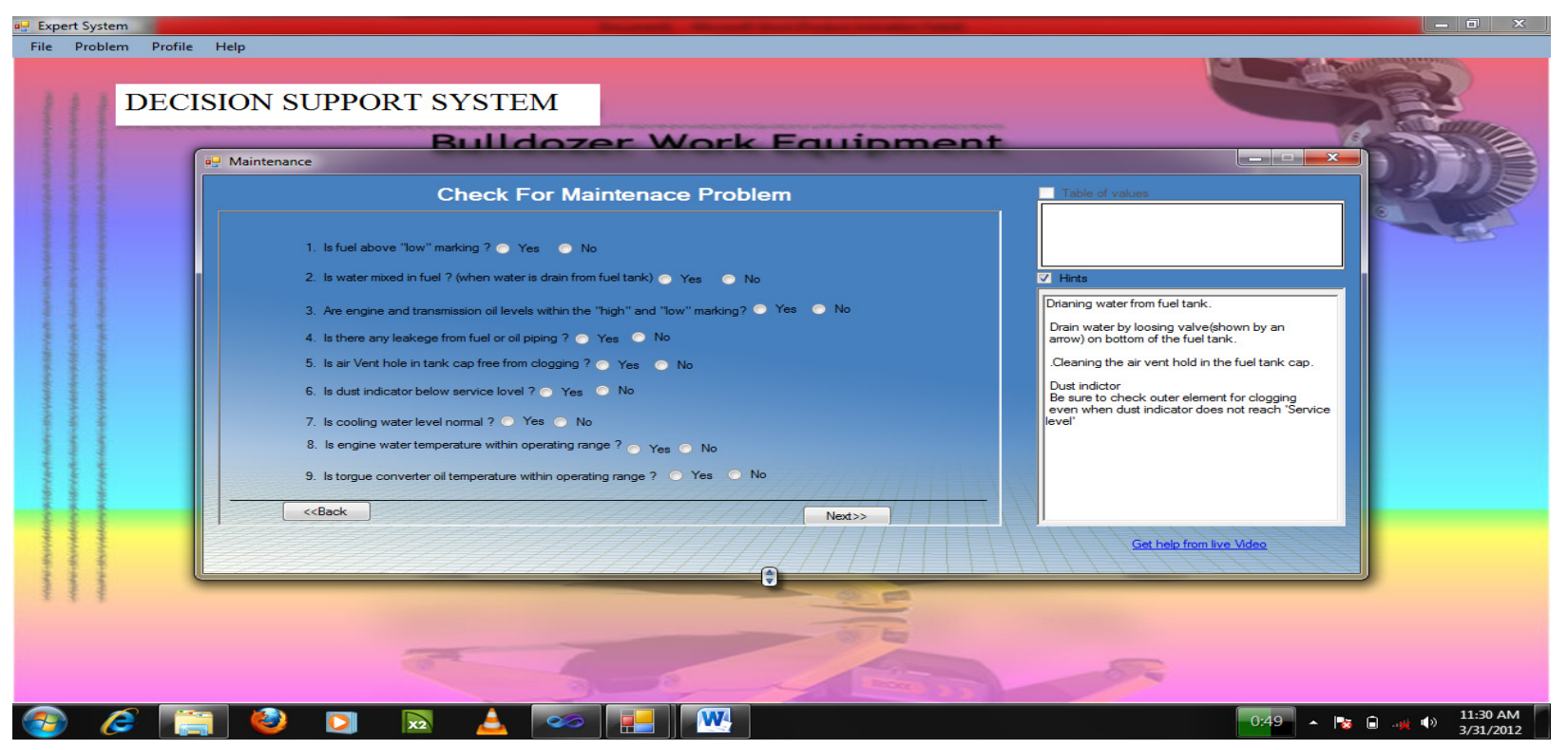

Figure 3. The maintenance problem section

The above Fig 3 describes the maintenance section of the program. As mentioned above, the operator is expected to have a prior knowledge of the fault detective in order to give the accurate answers that will enable the program to the requires solution in respect of the causing problem.

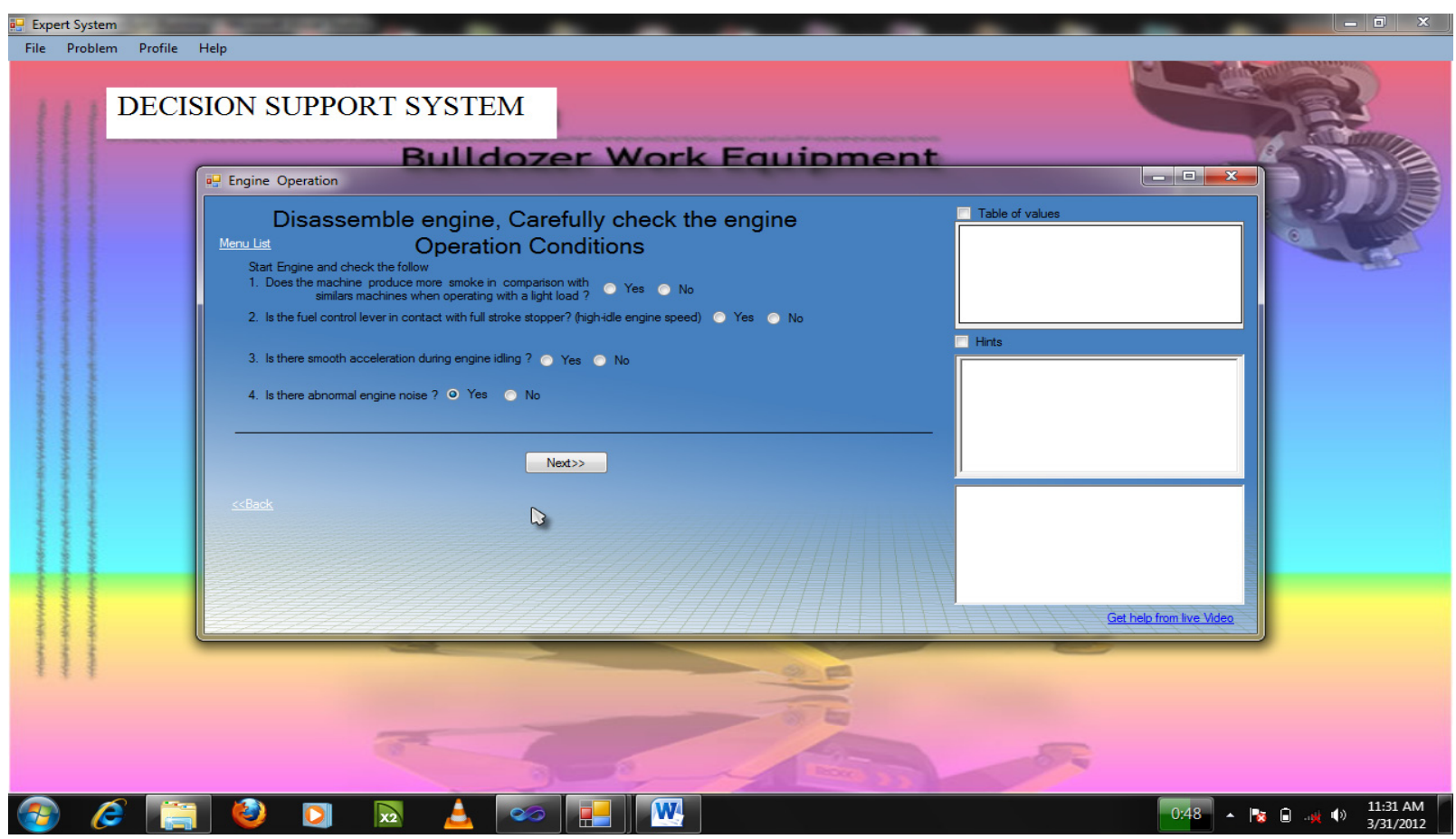

Figure 4. The checking for engine operation section

Figure 4 is another result page in the program which discusses and proffers solution for the engine operation condition. The operator is expected to start the engine and check if the machine produces more smoke in comparison with similar machine when operating with light loads. 


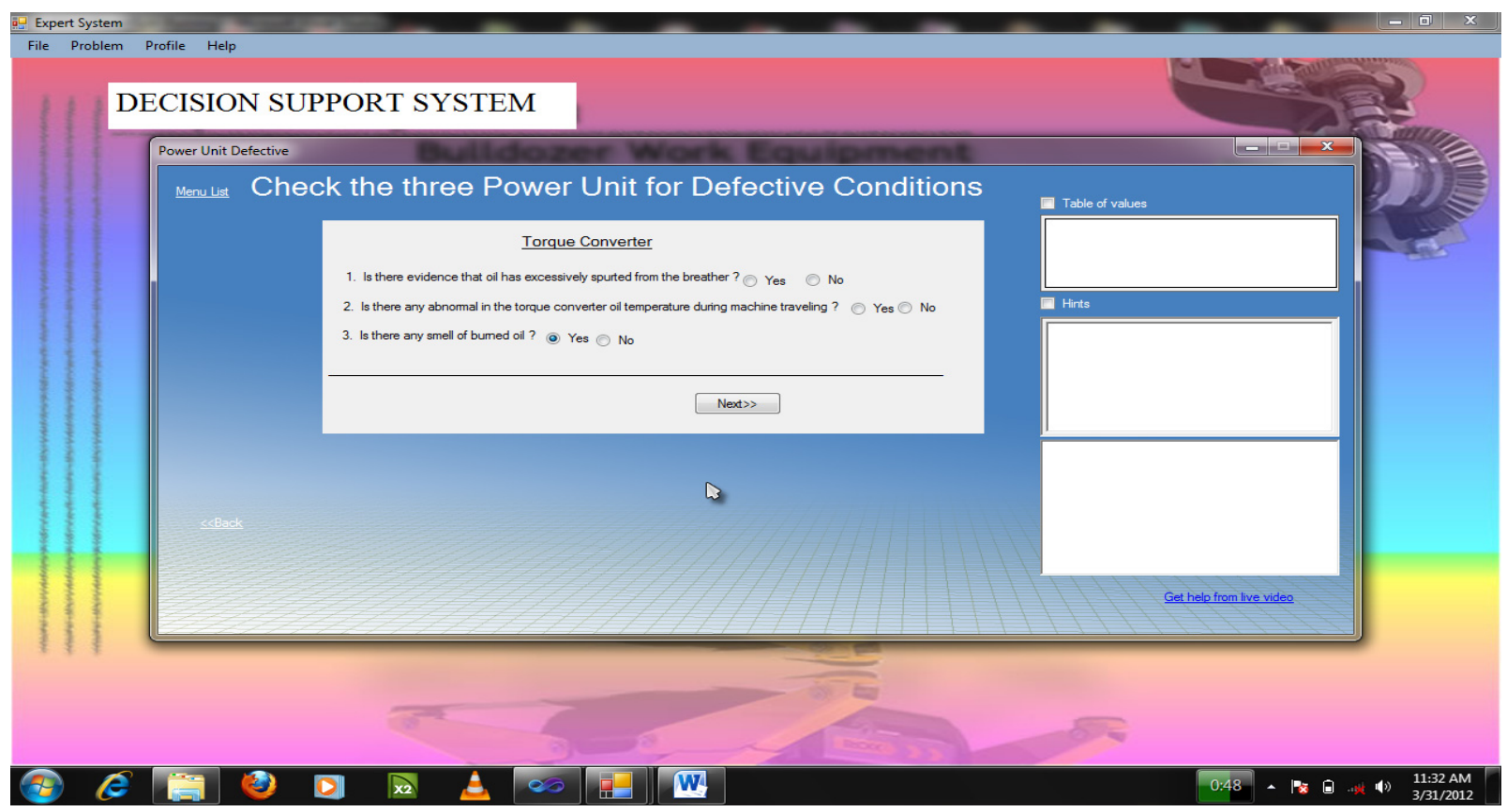

Figure 5. The power unit section

Figure 5 discusses the three power line units for defective conditions. The operator is expected to drive the machine to check for the following: is there any evidence that oil has excessively spurted from the breather, is there any smell in the burned oil? After which the program will proffer solutions to the respective questions asked.

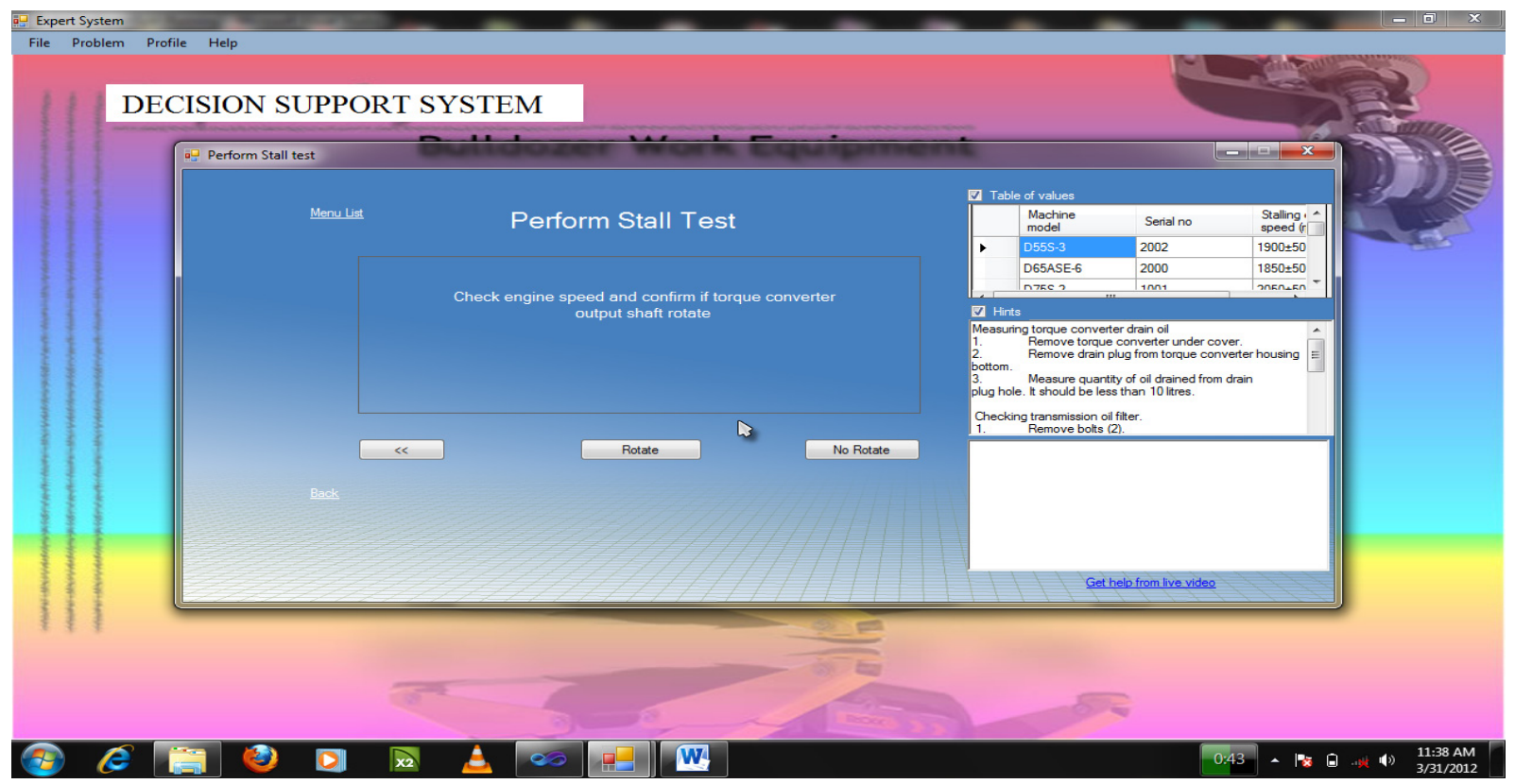

Figure 6. The performing of stall test section

This page discusses in details how to perform the stall test. It instructs the operator to warm up the engine by running it for 5 minutes at low idle, 3 minutes at medium speed and exactly one minute at high speed in order to check engine speed and confirm if torque converter output shaft rotates. 


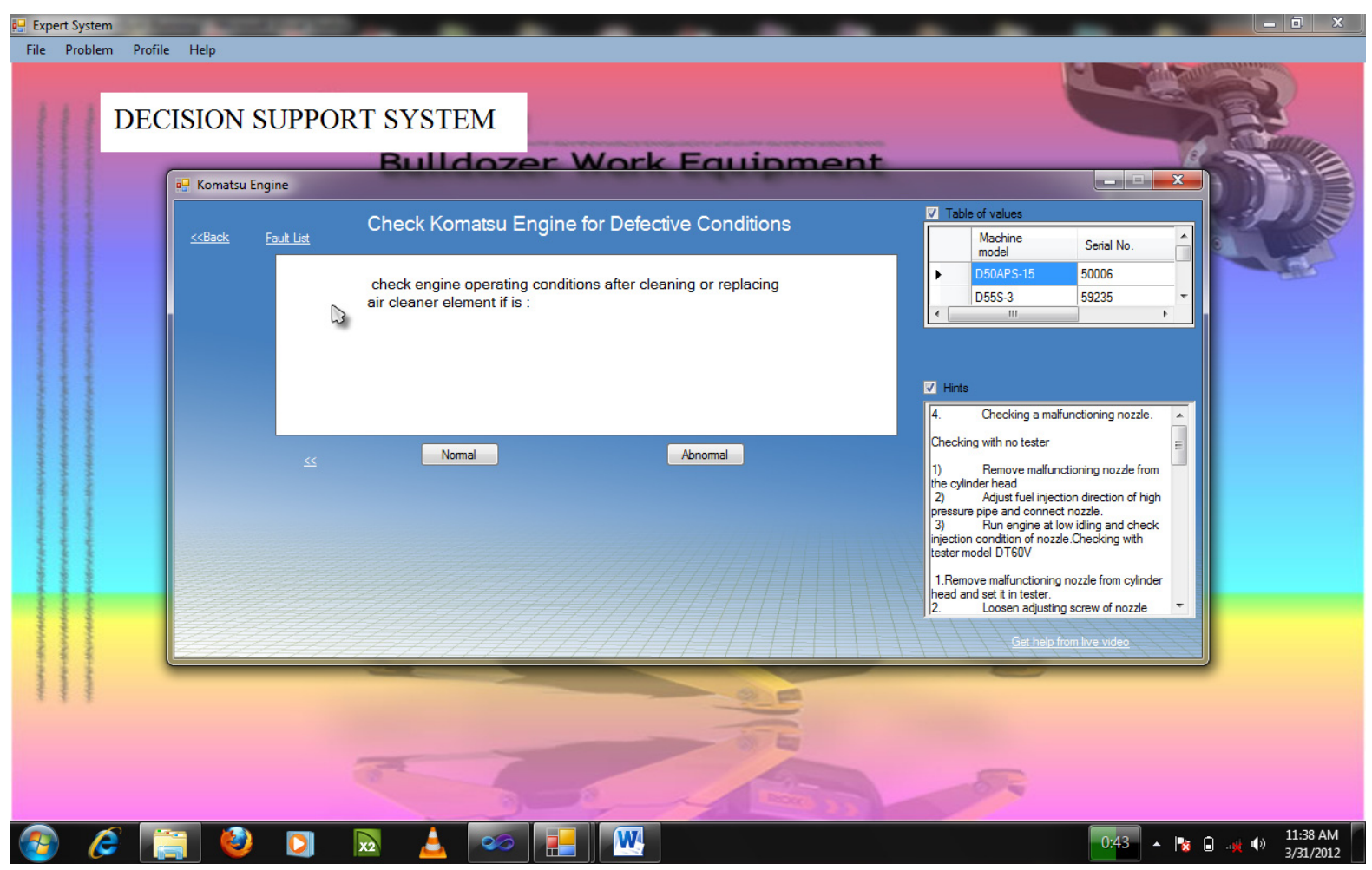

Figure 7. The checking of engine for defective condition stage

This page discusses in the checking of engine for defective conditions. It instructes the operator on how to clean the air container element, turbocharge blower clearance, checking turbocharger rotation, fuel stop testing, checking a malfunctioning nozzle.

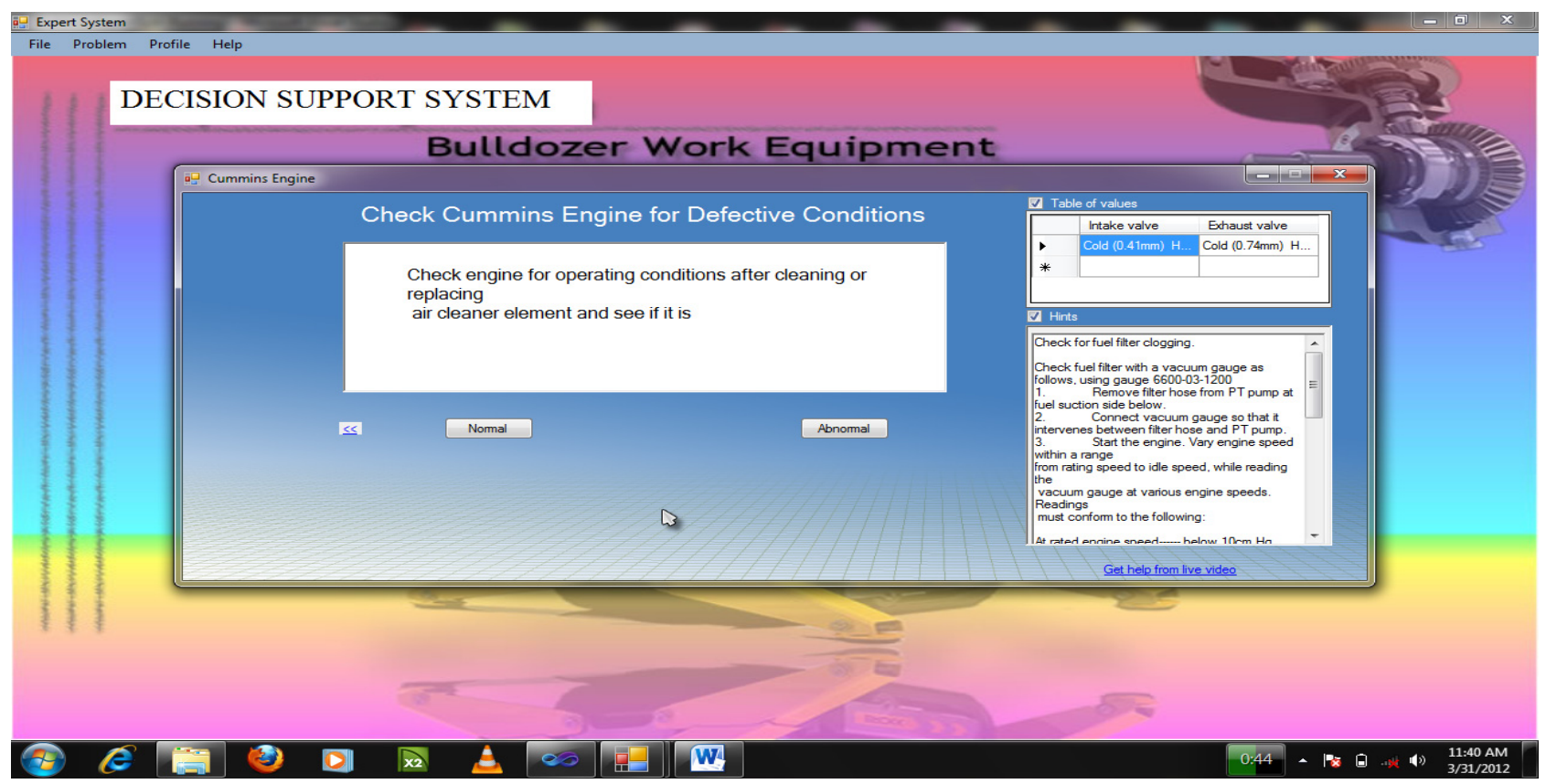

Figure 8 . The checking of cummins engine for defective conditions stage

At this stage, the program instructes the operator to check cummins engine for defective condition. Cleaning the 
air cleaner element, checking the clearance, checking the turbocharger rootation, checking fuel filter clogging.

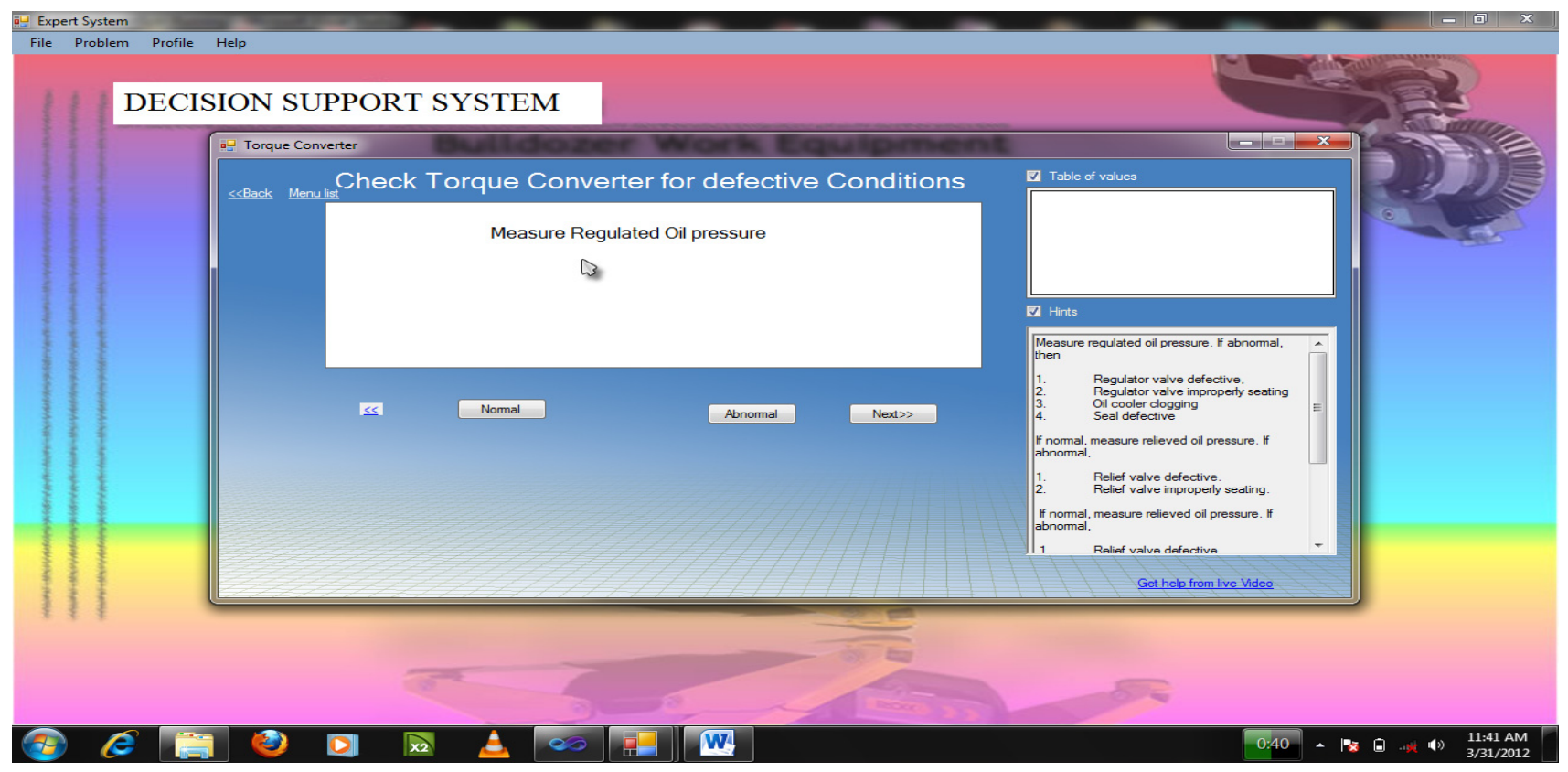

Figure 9. The checking of torque converter for defective conditions stage

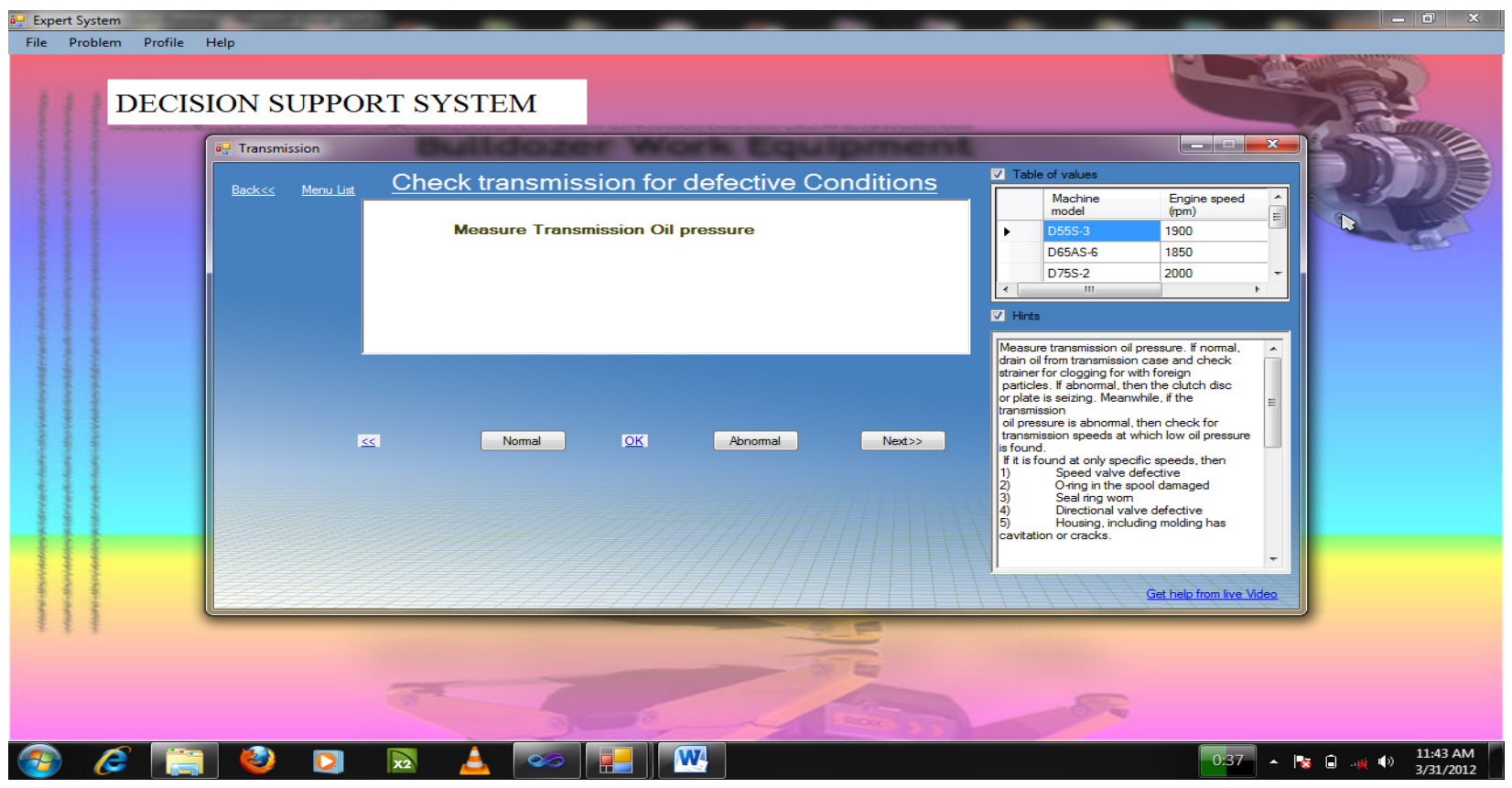

Figure 10. The checking of transmission for defective conditions stage

\section{Results}

In this section, the results of all the failures analysed and their respective procedures to solve the problems are shown and discussed in details. The program developed deals with the various failures in bulldozer work equipment failure and obviously shows the necessity for speedy, stress free and cost effective means of machine repairs. The Figure 1 is the concise of all the problems that can cause lack of sufficient power in bulldozer work equipment. 
This research work has established that: (i) power failure in earthmoving equipment (bulldozer) results from a number of causes and the causes have been identified. (ii) to troubleshoot power failure problem in bulldozer, a flowchart was used for algorithm development easier procedure and faster solution, prediction, (iii) the developed software (Decision Support System) and the mathematical model are faster, time saving, manpower reduction, quick in action and economical in solving power failure problem in work equipment. (iv) the developed software is able to predict the possible cause of power failure in bulldozer. (v) the results in equipment, manual and were found to be same (vi) the use of decision support system to solve power failure problem in bulldozer caused reduction in manpower, cost of hiring experts for repair and maintenance, increase assurance of project completion in time and is therefore applicable and recommended for use in manufacturing and construction industries where optimum profitable services are mostly expected.

\section{Discussions}

The results of the diagnosis by the decision support system shows that the various identified problems in this case study were proffered with solutions. The developed probability tree model used as tool for predicting solution(s) to the identified problems worked perfectly and was able to predict exact solution(s) as found in the manual of the machine under study.

The probability tables and the mathematical models were used to predict the possible cause of power failure and avoid doing the first thing last. From the job card problems, associated with the fuel fitter such as, fuel leakage, water mixed with fuel, element clogging has the highest number of occurrences indicating the highest number of time of cause of power failure that invariably confirms the information gathered from the fitter mechanics.

The causes of the power failure problems can easily be traced and diagnosed with data entry. The program is quick and faster in detecting faults and causes of power failure in the work equipment than human experts. It makes the troubleshooting to be stress-free and eliminate trial-and-error which may result to damage of work equipment parts. The maintenance process in this decision support system changed from the old concept of fix-it-when-it-broke to a more complex approach, which entails a better maintenance strategy of a more integrated approach. The program will enable the parts of the power system to be assessed and the conditions can be evaluated easily and quickly without necessarily seeing the parts or removing them. This will enable operators and engineers to solve power failure problem quickly and faster and eventually reduce down time to the barest minimum.

Any development is an endless process. Although, so many expert systems and decision support systems have been developed over the years, there are still more opportunities to develop as many as possible in different fields addressing various problems that can be found in such field.

For example, in this work, information utilized to develop the program has been used independently and the results have increased performance in machines.

The major work that can be done in this respect is to develop more decision support systems that can accommodate several kinds of problems and their respective solutions.

Further software can be developed which can detect failure, analyze it and proffer the solution automatically in other machines apart from this case study (bulldozer). This will increase assurance of project completion in time, reduced cost of hiring experts for repair and maintenance and also create an optimized profile that can be used for absolutely easy problem solving environment in the engineering world.

\section{References}

Akinnuli, B. O. (2009). Development of Models for Machinery evaluation in manufacturing industries (pp. 22-44). Unpublished PhD Thesis, Department of Mechanical Engineering Federal University of Technology, Akure, Nigeria.

Akinnuli, B. O., \& Olaleye, J. O. (2013). An Expert system for Diagnosing and proffering solutions to causes of overheating in a Bulldozer Engine (Case Study Model D6OS-6 Komatsu Products). Engineering Management Research, 2(2), 56-65. http://dx.doi.org/10.5539/emr.v2n2p56

Bylander, T. S., Mittalk, B., \& Chandrasekarai, C. S. (1983). A Language for Expert Systems for Diagnosis in Proceedings (pp. 16-18).

Charles, O. (2002). Details of the Revised Therapy Algorithm. In B. G. Buchanan, \& E. H. Shortliffe (Eds.), Rule Based Expert Systems. Addition Wesley.

Corneliue, T. L. (2002). Expert System. The technology of Knowledge management and decision making for the $21^{\text {st }}$ century. Addison Wesley. Federation of American Scientist, Military Analysis Network, (FASMAN) 
(2006): Diesel Engines. Retrieved February 10, 2013, from http://www.fas.org/man/dod-101/sys/ship/eng /diesel.htm

Fijany, A., Vatan, F., Barrett, A., \& Mackey, R. (2002). New Approaches for Solving the Diagnosis Problem IPN Progress Report 42-149. Retrieved March 14, 2013, from http://tmo.jpl.nasa.gov/progress

Fink, P. K., Lusth, J. C., \& Duran, J. W. (1984). A General Expert System Design for Diagnostic Problem Solving. In Proceedings of Institute of Electrical Electronics Engineering (IEEE) Workshop. Principles of Knowledge Based Systems.

Ganglui, S., Deo, S., \& Gorinevsky, D. (2004). Parametric Fault Modeling and Diagnostic of a Turbofan Engine. IEEE CCA/ISIC/CACSD. Taiped, Taiwan. Retrieved March 22, 2013, from http.//www.standard.edu/gorin/papers/CCA04gls.pdf

Garcia, M., John, C., \& William, S. (2004). PUMPX: An Expert System for Pump Diagnosis. Retrieved March 22, 2013 from http://fie.engrng.pitt.edu/fie 2004/papers/1009.pelf

Hefmann, M., Cariedes, J., Bourne, J., \& Beale, G. B. (1988). Building Expert systems for repair domains. Expert systems (pp. 120-124). Prentice hall.

Lars, E. (2004). Structural Algorithms for Diagnostic System Design Using Simulation Models. Master's Thesis. Vehicular System, Department of Electrical Engineering, Linkoping, University.

Leo, O. (1992). Diagonosing Diesel Engines. Mechanical Engineering-Cime. Retrieved May 2, 2013, from $\mathrm{http}: / /$ www.allbusiness.com/periodicals/article/295719-1

Lugar, G., \& Stubblefield, W. (2004). Artificial Intelligence: Structures and Strategies for Complex Problem Solving (5th ed.). The Benjamin/ Lummings Publishing Company, Inc.

Newton, K., Steeds, W., \& Garrett, T. K. (1983). The Motor Vehicle (10th ed., pp. 27-32). Butterworths.

Nyberg, M (1999). Model Based Faulty Diagnosis Methods. Theory and Automotive Engine Applications. Department of Electrical Engineering, Linkoping University, SE-581 83 Linkoping, Sweden. Retrieved June 22, 2013, from http://www.vehicular.isy.liu.se/publications/PhD/99

Olmostadt, W. (2000). Cataloging Expert Systems: Optimisms and Frustrated Reality. Journal of Southern Academic and Special Librarianship, 16-25.

Olofsson, N. (2000). Evaluation of Observers for Fault Diagnosis on an Automotive Engine. Retrieved July 16, 2013, from http://www.vehicular.isy.liu.se/publications/MSc/00 EX3118 NO.pdf

Sauter, D (2006). Technical Faulty Diagnosis and Fault Tolerant Control. University Henri Poincare, Nancy-0CRAN. Retrieved August 20, 2013, from http://kepo.hut.fi/files/2006

Stuan, C. (2006). Expert System for Steel Bridge Super-Structure Inspection and Evaluation. Research and Innovative Technology Administration of the U.S. Department of Transportation. Retrieved September 25, 2014, from http://www.utrc2.org/research/assets/41/expertinspection1.pdf

Walwij K, V. (2000). Is there a future for the diesel engine in automoyive application? Innas/Diesel/future presentation. Windsor workshop. Retrieved September 25, 2014, from http://www.windsorworkshop.ca /downloads/Martin Van Walwji.pdf

Waterman, D. A (1986). A Guide to Expertn Systems Addison- Wesley, Reading, MA, (All85) All, M., D.A. Scharnhorst. Sensor-based Faulty Diagnosis in a Flight Expert System. In Proceedings of the Second Conference on At Appliocations.

Ying, S. (1998). Diagnosis. Dependable Embedded Systems. Carnegie, Mellon University. Retrieved October 16, 2014, from http://www.ece.cmu.edu/koopman/des s99/diagnosis prognosis/index.html

\section{Copyrights}

Copyright for this article is retained by the author(s), with first publication rights granted to the journal.

This is an open-access article distributed under the terms and conditions of the Creative Commons Attribution license (http://creativecommons.org/licenses/by/3.0/). 